DOI: $10.2478 / v 10077-011-0020-x$

\author{
J. W. Shanafield ${ }^{1}$, A.W. Otieno ${ }^{1}$, R. A. Tatara ${ }^{1}$, D. J. Schroeder ${ }^{1}$, and K. A. Rosentrater ${ }^{2}$ \\ 1 -Northern Illinois University, Department of Technology, DeKalb, IL, USA, \\ tatara@ceet.niu.edu \\ 2 -North Central Agricultural Research Laboratory, United States Department of \\ Agriculture, Brookings, SD, USA
}

\title{
SURFACE ROUGHNESS AND DIAMETRAL CONSISTENCY OF HOLES DRILLED INTO DDGS/PHENOLIC RESIN BLENDS
}

\begin{abstract}
In this study, corn-based distillers dried grains with solubles (DDGS) has been utilized as a filler and blended with phenolic resin. The blends were compression molded into rectangular test specimens, into which holes have been machined using a standard $9.52 \mathrm{~mm}$ (3/8 in) diameter, two-fluted twist drill. A series of tests was then conducted to examine the effects of DDGS content, cutting speed, and feed rate upon the surface finish (roughness) of the interior hole slot, as well as the consistency of the drilled hole diameter. DDGS content was $0,25,50$, and $75 \%$, by weight. Cutting speed was 17,30 , and $46 \mathrm{~m} / \mathrm{min}$ (55, 100, and $150 \mathrm{ft} / \mathrm{min}$ ). Feed rate was $0.025,0.152$, and $0.279 \mathrm{~mm} / \mathrm{rev}$ (0.001, 0.006, and $0.011 \mathrm{in} / \mathrm{rev}$ ). Results indicate that as the DDGS content increased, roughness exhibited a weak but statistically significant decrease. When the cutting speed increased, roughness increased slightly. However, when feed rate increased, roughness increased at a greater rate than that due to cutting speed. In terms of diametral consistency, the effect of adding DDGS resulted in holes with diameters less than the nominal drill size. As cutting speed increased, the holes tended to be oversized. Based on the cutting speed and feed rate levels used, optimal machining conditions which would reduce roughness occurred for $75 \%$ DDGS, cutting speed of $17 \mathrm{~m} / \mathrm{min}$ (55 $\mathrm{ft} / \mathrm{min})$, and feed rate of $0.025 \mathrm{~mm} / \mathrm{rev}(0.001 \mathrm{in} / \mathrm{rev})$. However, to maintain consistent hole diameter, optimal conditions were found to be $40 \%$ DDGS, $30 \mathrm{~m} / \mathrm{min}(100 \mathrm{ft} / \mathrm{min})$, and $0.152 \mathrm{~mm} / \mathrm{rev}(0.006 \mathrm{in} / \mathrm{rev})$ and would produce a drilled hole with a diameter of $9.52 \mathrm{~mm}(0.375 \mathrm{in})$. As the use of biofillers in plastic composites evolves, it will become increasingly important to examine the machinability of these novel materials.
\end{abstract}

Key words: biofiller, bioplastics, composites, machinability, drilling

\section{INTRODUCTION}

There is an increasing amount of attention being devoted to the use of biologically-derived materials, especially co-products from biofuel production [1], in industrial products. This is partly to reduce dependency on petroleum-based (non-renewable) materials, and additionally to increase sustainability. An added benefit is that any bio-based component of a part or product can enhance potential biodegradability at the end of the product's useful life. Many plastic products 
already use wood flour as a bio-based filler, and there are numerous other biofillers already in application or proposed for use [2].

One common industrial plastic is phenolic, and its resins are produced by chemically combining phenol and formaldehyde through a condensation reaction under alkaline conditions. Phenolic resin is a thermosetting plastic, which reacts during processing to form cross-linked structures that cannot be remelted or reprocessed. Prior to processing, fillers and additives are added to produce standard phenolic molding compounds. Inorganic as well as organic fillers and reinforcements mix well with phenolic resins.

Generally, fillers are inert materials added to a plastic to reduce the cost of the final product by replacing a portion of the polymeric resin and improving properties such as strength, hardness, or stiffness. To achieve substantial cost savings, fillers must be added in relatively large concentration while maintaining adequate mechanical and physical properties. Fillers can be organic, inorganic, natural, synthetic, or mineral in nature. Common fillers are clay, talc, ground limestone, carbon black, marble, dust, glass, paper, wood flour, and metals, and they are commonly added in concentrations ranging from $10 \%$ to $60 \%$ by weight. Appropriate selection of filler is based on cost, availability, compatibility with the resin, effects on product properties, abrasiveness, effect on processing, moisture absorption, and other factors. Examples of bio-based fillers include wood flour, sugar cane, lignin, flax, grasses, bamboo, starch, chicken feathers, soy protein, and cellulose. Wood flour is the oldest biofiller utilized in plastics, and is commonly blended to form wood-plastic composites.

Corn processing co-products are also potential bio-based fillers. They are the non-fermentable remnants after the starch fraction of corn is fermented with yeasts and enzymes to produce fuel ethanol and carbon dioxide. Common co-products include distillers dried grains (DDG), distillers dried grains with solubles (DDGS), condensed distiller solubles (CDS), and distillers wet grains (DWG). These materials are generally considered low-value commodities to be disposed of; typical use is animal feed. Use of co-products as biofillers will create additional markets for the agricultural industry. DDGS has already been blended with phenolic to produce biocomposites [3].

After molding, many plastic parts require some form of secondary operation, in many cases machining and/or finishing. Thus it is useful to further determine machining qualities of these novel plastic products. Although considerable data exist concerning physical, mechanical, and engineering properties of plastics with biofillers, other engineering characteristics such as machinability have only been recently examined. Rosentrater et al. [4] machined rectangular slots on DDGS-filled phenolic specimens with a $13 \mathrm{~mm}$ (1/2 in) diameter two-fluted end-mill. The specimens used were identical to those used in this study. Blends of 25\% and 50\% DDGS were examined. The cutting speed varied from 120 to $160 \mathrm{~m} / \mathrm{min}$ (394 to $525 \mathrm{ft} / \mathrm{min}$ ); the feed rate varied from 200 to $300 \mathrm{~mm} / \mathrm{min}$ (7.9 to $11.8 \mathrm{in} / \mathrm{min}$ ); and the depth of cut was fixed at $2 \mathrm{~mm}$ (0.08 in). The resulting surface roughness was measured with a surface profilometer. The data showed that with 25\% DDGS, higher cutting speeds and lower feed rates resulted in a smoother surface finish. For the 50/50 blend, less roughness occurred with lower speeds and higher feeds. It was determined that the overall machinability of the DDGS-filled plastic depended greatly upon the level of DDGS used.

A frequent machining operation is producing holes with a twist drill, commonly known as drilling. To date, however, no studies have examined drilling on DDGS-based composites. Thus the objectives of this research were to fabricate DDGS-phenolic resin composites, to examine the 
effects of DDGS level, drilling speed, and feed rate on the surface finish and the consistency of drilled holes, and to establish optimal drilling conditions for these specimens.

\section{MATERIALS AND METHODS}

For this study, distillers dried grains with solubles was obtained from a commercial dry-grind ethanol plant in South Dakota. It is composed of $12.3 \%$ moisture content (on a dry basis), a protein content of $27.6 \%$, a fiber content of $11.1 \%$, a lipid content of $9.3 \%$, an ash content of $4.2 \%$, with other carbohydrates of $47.8 \%$. This DDGS was utilized in its raw, untreated form and is a coarse powder having an average particle size of approximately $1 \mathrm{~mm}$ (0.04 in), consistent with a recent survey of grains from three different ethanol plants [5] that showed mean particle diameters ranging from 0.69-1.19 mm (0.03-0.05 in). The grains are soft and easily deformed or crushed upon which oils are released. The resin consisted of phenolic and its catalyst, hexamethylene tetramine, in concentration (by weight) of $91.5 \%$ and $8.5 \%$, respectively, without any of the other standard phenolic molding compound additives, in order to isolate the effects of DDGS as a filler.

DDGS/resin blends of $0 \%$ (pure resin), 25\%, 50\%, and 75\% were prepared for molding. The DDGS filler was added by weight and was mixed with phenolic resin in a small plastic cup with $90 \mathrm{sec}$ of stirring. The resin charge for each specimen was $45 \mathrm{~g}$ (1.6 oz). The resin and DDGS powders were simply physically mixed without any chemical reaction or treatment prior to the compression molding process. Chemically reacting the filler with the resin is known to improve the strength of the final molded product, but this can be a complex activity, and when promoting use of co-products (such as DDGS) costs are minimized when they are utilized directly from an ethanol plant in their raw, untreated form. It should be noted that these blend ratios were previously molded and tested for mechanical strength [3]. Results demonstrated tensile yield strengths ranging from 4.3 MPa (621 psi) to $14.5 \mathrm{MPa}$ (2102 psi), while the Young's modulus ranged from $841 \mathrm{MPa}(122,000 \mathrm{psi})$ to $2296 \mathrm{MPa}(333,000 \mathrm{psi})$ as the DDGS content decreased from $75 \%$ to $25 \%$. At $25 \%$ DDGS, the tensile yield strength was approximately half that of the pure resin. Increasing DDGS content further reduced the strength to nearly one-quarter (at 50\% DDGS), and under one-sixth (at 75\% DDGS) compared to the 100\% phenolic baseline.

\section{COMPRESSION MOLDING OF TEST SPECIMENS}

In compression molding, a resin charge is placed into the lower half of a mold cavity, then the mold is closed to seal the charge. Depending upon the charge material used, a combination of pressure and temperature initiates the curing reaction in the sample, and causes it to harden into a formed part conforming to the shape of the mold cavity. Compression molding is commonly employed for thermosetting resins such as phenolics, polyesters, and epoxies, and works well

with filler and reinforcing fibers. Compared to other plastics molding processes, such as injection 
molding and extrusion, the filler in compression molding is subjected to minimal shear, as the filler is compressed along with the resin and thus has a very short flow path. The aluminum mold used for this study could mold a single test specimen at a time (Fig. 1). It measured $102 \mathrm{~mm}$ (4 in) long, $89 \mathrm{~mm}$ ( $3.5 \mathrm{in})$ wide, and $64 \mathrm{~mm}$ (2.5 in) in height when closed. The ejector plate is also shown in Fig. 1; when molding, the plate is seated into the lower mold half, covering the ejection holes. Once the specimen molding is complete, the mold halves are separated and ejector pins measuring $6.35 \mathrm{~mm}$ (1/4 in) diameter by $25 \mathrm{~mm}(1 \mathrm{in})$ long - are inserted into the bottom of the lower half to force out the ejector plate, thus pushing out the molded part.

Compression molding was accomplished using a 267-kN (30-ton) heated press. The molding procedure began by placing the closed mold (containing a specific blend) into the unheated press at room temperature $\sim 25^{\circ} \mathrm{C}\left(77^{\circ} \mathrm{F}\right)$; pressurizing to $47.6 \mathrm{MPa}(6900 \mathrm{psi})$; and then activating the press heaters until $196{ }^{\circ} \mathrm{C}\left(385{ }^{\circ} \mathrm{F}\right)$ was reached, at which time the material began to cure. This entire molding cycle required about $30 \mathrm{~min}$. (Due to the presence of moisture in the raw DDGS, it was necessary to begin the molding process with the mold and press platens at room temperature.) The mold was then removed from the press, cooled, and the specimen was ejected using the ejector pins.

\section{DRILLING}

After molding, the specimen was removed, and its edges were ground to remove flash. Each final specimen measured $51 \mathrm{~mm}$ ( 2 in) by $76 \mathrm{~mm}$ (3 in) by $9.5 \mathrm{~mm}$ (3/8 in). Fig. 2 shows a typical test specimen. Test holes were drilled into the specimens according to a full factorial Design of Experiment (DoE) methodology with four levels of DDGS, three levels of speed, and three levels of feed rate with three replicates of each drilling condition that required a total of twelve specimens. Complete experimental details and molding procedure are available [6].

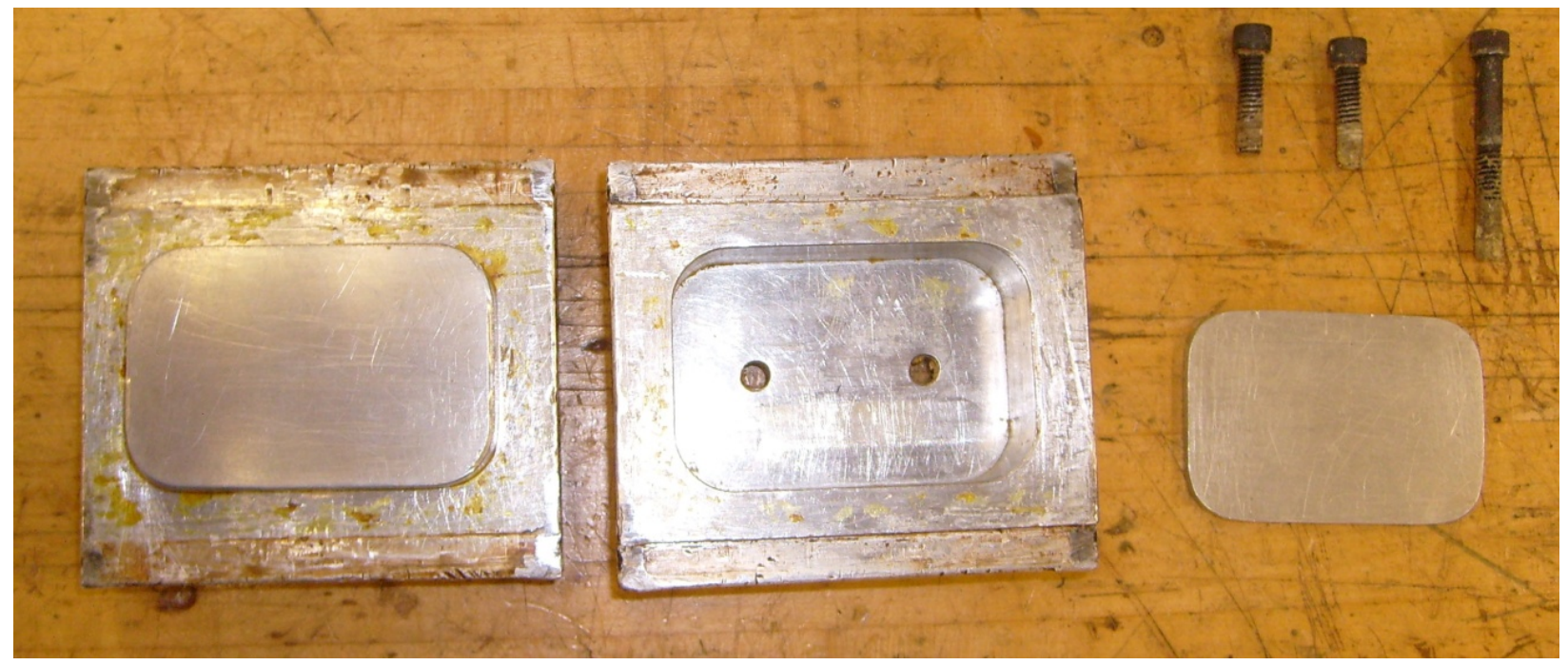

Fig. 1. Test specimen compression mold with ejector plate 
The drilling process utilized a CNC machine with a $9.52 \mathrm{~mm}$ (3/8 in) high-speed-steel (HSS) twist drill bit. To eliminate tool wear as a variable, a new bit was used for each of the twelve specimens. Every bit was verified to be true nominal size before use. The geometry for the twist drill is shown in Table 1; the table includes industry-recommended values for same-size drilling of thermosetting plastics reinforced with a paper or cotton [7]. Fig. 3 displays the pertinent angles and edges for a standard $118^{\circ}$ twist drill. The drilling was performed dry, but no excessive heat was noted in the specimen or bit after drilling. Chips were dry, flat, segmental, and small - about 2-3 mm (0.08-0.12 in).

Table 1. Twist drill geometry and drilling conditions*

\begin{tabular}{|c|c|c|}
\hline & Lokensgard [7] & Present study \\
\hline \multicolumn{3}{|l|}{ Drill Geometry } \\
\hline Diameter, mm (in) & $9.52(3 / 8)$ & $9.52(3 / 8)$ \\
\hline Shaft length, mm (in) & - & $38.1(1.5)$ \\
\hline Flute length, mm (in) & - & $102(4.0)$ \\
\hline Rake angle $\left({ }^{\circ}\right)$ & 25 & 25 \\
\hline Point angle $\left({ }^{\circ}\right)$ & $90-120$ & 118 \\
\hline \multicolumn{3}{|l|}{ Drilling Conditions } \\
\hline Clearance angle $\left({ }^{\circ}\right)$ & $10-15$ & 12 \\
\hline Rake angle $\left(^{\circ}\right)$ & 0 & 0 \\
\hline rpm & 960 & $509-1528$ \\
\hline Cutting speed, $\mathrm{m} / \mathrm{min}(\mathrm{ft} / \mathrm{min})$ & $29(95)$ & $17,30,46(55,100,150)$ \\
\hline Feed rate, mmpr (ipr) & $0.14(0.006)$ & $\begin{array}{l}0.025,0.152,0.279(0.001,0.006 \\
0.011)\end{array}$ \\
\hline
\end{tabular}

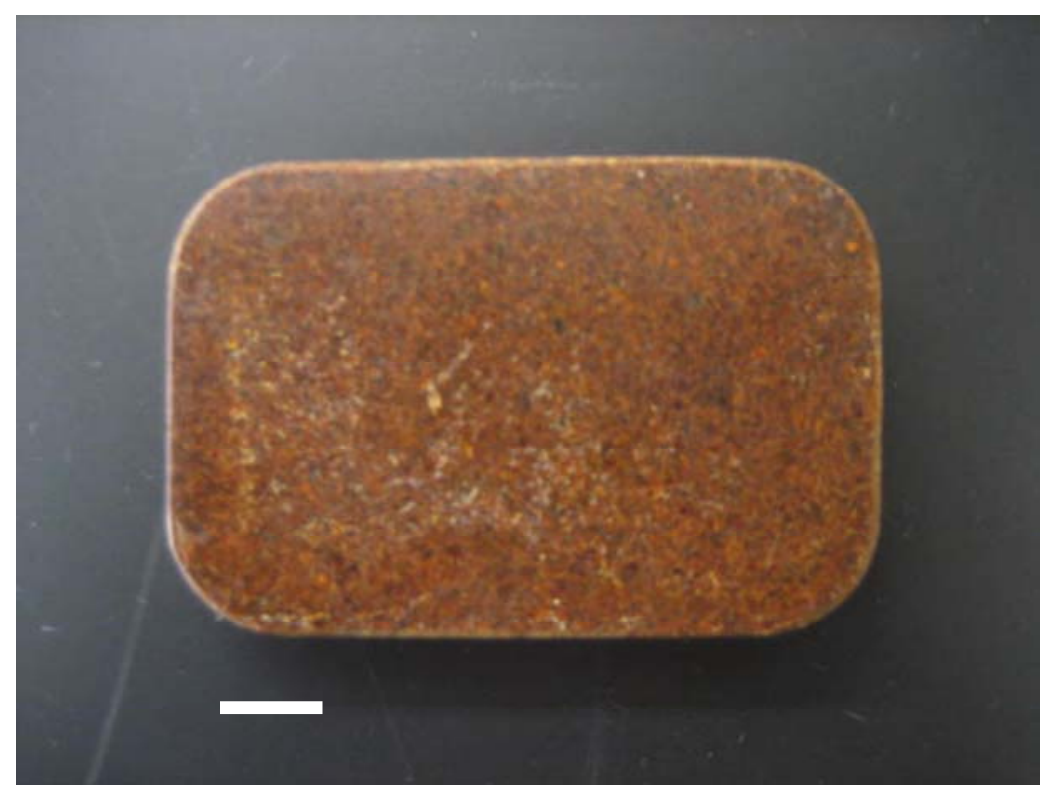

Fig. 2. Typical DDGS/phenolic compression-molded test specimen; scale bar indicates $10 \mathrm{~mm}$ (0.39 in) 


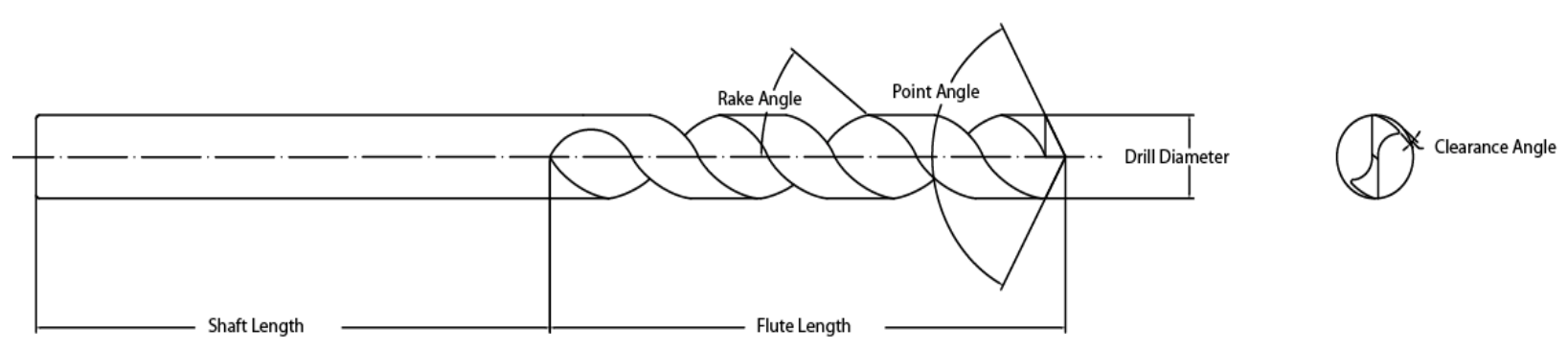

Fig. 3. Schematic view of twist drill geometry

\section{MEASUREMENT OF SURFACE ROUGHNESS AND DIAMETRAL CONSISTENCY}

Following drilling, the specimens were examined for hole quality (roughness of drilled hole's interior), hole diameter tolerance, and finish of the entry and the exit of the hole. A Mitutoyo ${ }^{\mathrm{TM}}$ SJ-301 surface profilometer was used to measure the surface roughness. Calibration of the instrument was done with a standard specimen with known roughness prior to the experimentation. For each measurement, the specimen was held vertically and the stylus inserted into the center of a hole. The stylus of the profilometer extended at a $90^{\circ}$ angle to the bottom dead-center and measured the roughness from entry to exit. Fig. 4 is a photographic view of the specimen mounted into the profilometer fixture.

For hole diameter consistency evaluation, a coordinate measuring machine (CMM) was used to acquire physical measurements. The test specimen was mounted horizontally into a springloaded fixture. The CMM probe was centered and lowered into the hole to a depth of $4.8 \mathrm{~mm}$ (3/16 in) - midpoint of the hole's depth. At this location, four readings were obtained from the probe at evenly spaced points, to locate the circumference of the drilled hole. From this circumferential measurement, the hole's diameter was established. Minitab ${ }^{\circledR}$ software was used to perform statistical analyses on the resulting data.

\section{RESULTS}

Both roughness and hole diameter data were analyzed to determine which of the variables (DDGS content, cutting speed, and feed rate) and their interactions were statistically significant as to the quality of the drilled hole (i.e., surface roughness and diameter tolerance). For roughness, DDGS content, speed, feed, and the interaction between DDGS and feed were found to be statistically significant with $90 \%$ certainty - Figs. 5(a), 5(b), 5(c), 7. For hole diameter, DDGS, speed, the interaction between DDGS and feed, and the three-way interaction between all of the variables were also found to be significant with the same confidence level - Figs. 8(a), 8(b), 8(c). Best-fit functions were determined for both roughness and diameter. 
Fig. 5 shows the effects of DDGS, cutting speed, and feed rate on the average roughness. Shown are the averaged measured roughness data points; the statistically best-fit function; and error bars measuring the deviation between best-fit prediction and individual measured data. Typically the best-fit function predicts the average hole roughness within $10 \%$. The fit was best for feed - Fig. 5(c). Also from Fig. 5(c), it is apparent that feed had the strongest effect on roughness, approximately doubling the roughness between the lowest and highest feed rates. Fig. 5(a) demonstrates a small, but statistically significant, decrease in roughness as more DDGS is blended into the phenolic. It appears that the zero DDGS case is rougher than all samples containing DDGS which have an approximately constant level of roughness, though this trend is not clear enough to justify deviating from the linear model. Increasing drilling speed produces a more pronounced effect on roughness with 30\% rougher holes produced as the speed increases from 17 to $46 \mathrm{~m} / \mathrm{min}$ (55 to $150 \mathrm{ft} / \mathrm{min}$ ). Fig. 6 shows a 30X image of the side view of a drilled slot wall for two samples. Fig. 6(a) is 0\% DDGS at the highest cutting speed while Fig. 6(b) represents $75 \%$ DDGS at the lowest speed. The slots are positioned side-by-side and exit-to-exit. The specimen without DDGS shows pits on the order of $0.25 \mathrm{~mm}(0.010 \mathrm{in})$ in diameter while the 75\% DDGS specimen appears to be smoother with some smearing from the action of shearing the grain particles; no pits are visible. This smearing action may be responsible for the lower roughness measured on DDGS-containing samples. The breakout at the hole exits is typical for all of the samples in this study.

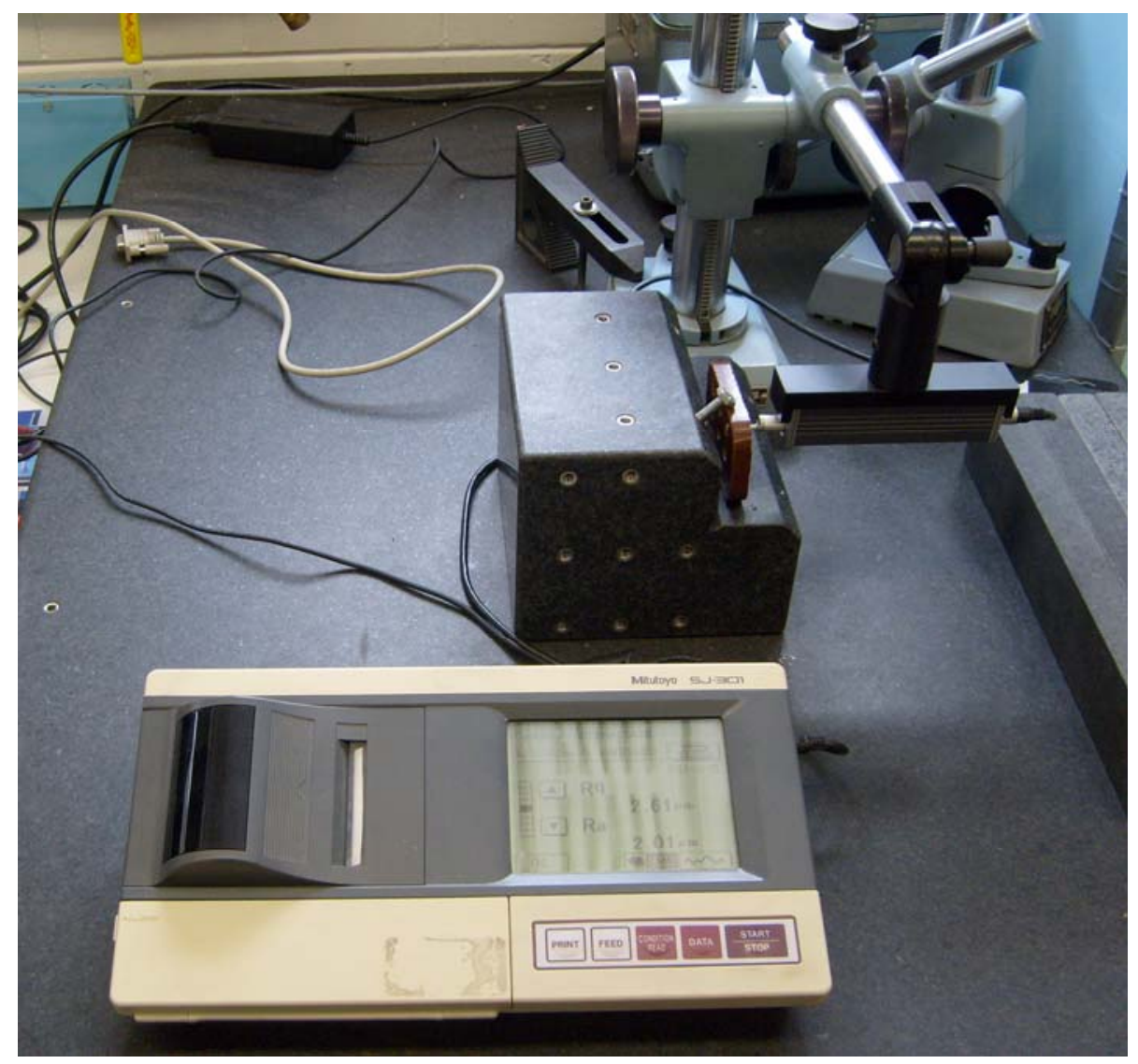

Fig. 4. Surface roughness measuring apparatus 
a) DDGS concentration

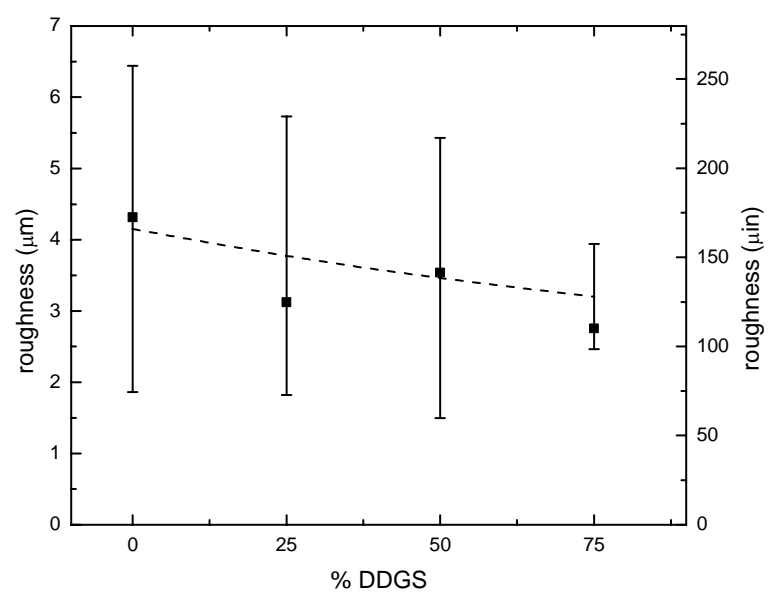

b) Cutting speed

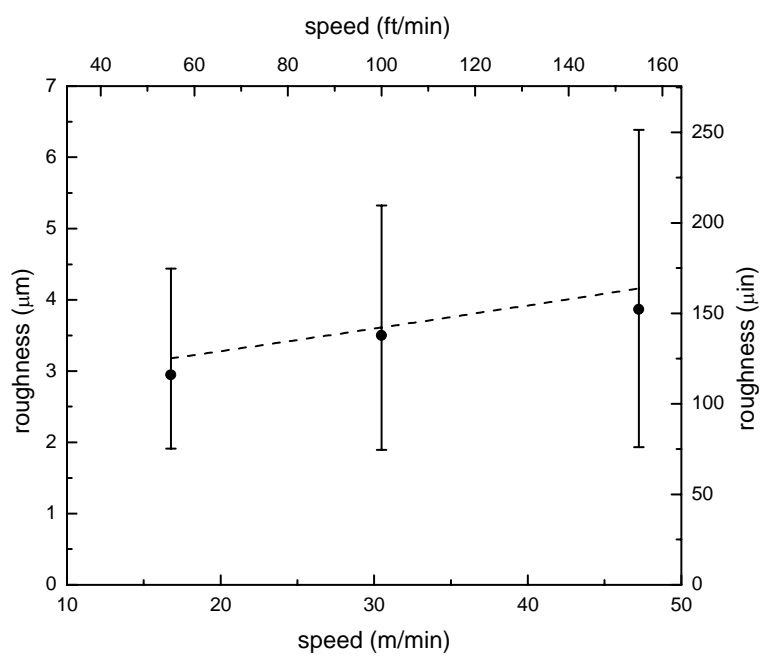

c) Feed rate

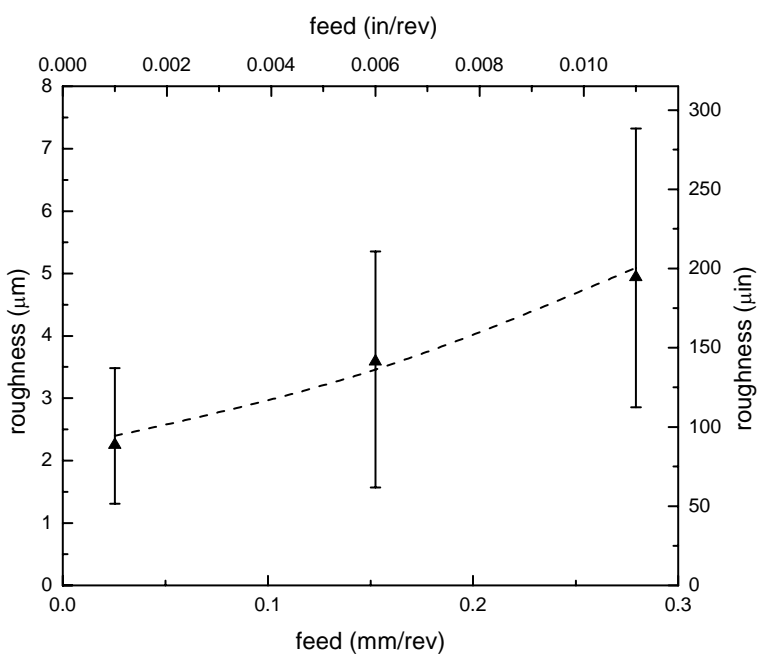

Fig. 5. Effects of drilling parameters upon roughness: dashed line represents best-fit function - Eq. (1) 
During multiple linear regression of the entire roughness data set, it was found that the error of the fit increased with increasing roughness, therefore the data were transformed by taking their natural logarithm. The transformation was successful in removing the trend and residuals appeared to be normally distributed. The best-fit was thus:

$$
\ln (\text { roughness })=\mathrm{A}+\mathrm{B}(\text { DDGS })+\mathrm{C}(\text { speed })+\mathrm{D}(\text { feed })+\mathrm{E}(\text { DDGS } \cdot \text { feed })
$$

where $\mathrm{A}=0.850 ; \mathrm{B}=-0.0102 ; \mathrm{C}=0.00932 ; \mathrm{D}=1.725$; and $\mathrm{E}=0.0366$, while roughness is in units of $\mu \mathrm{m}$, DDGS in \% (by weight), speed in $\mathrm{m} / \mathrm{min}$, and feed in $\mathrm{mm} / \mathrm{rev}$. The coefficient of determination $\left(\mathrm{R}^{2}\right)$ for this fit was 0.40 . This relatively low value was primarily due to variability between replicates rather than deviations between the fit and the average values at a given condition. The average roughness for the entire data set was $4.06 \mu \mathrm{m}$ (160 $\mu \mathrm{in})$, while the mean standard deviation of the replicates was $1.60 \mu \mathrm{m}$ (63 $\mu$ in).

Fig. 7 shows the effect of feed rate at different levels of DDGS. Points in the figure represent averages of experimental points across different speeds at the given feed rates. At $0 \%$ DDGS there was essentially no effect of the feed rate on the resulting roughness, but at all higher values of DDGS, increasing feed rate did increase roughness. At low feed rate, however, roughness was decreased significantly by the presence of DDGS. Because of this crossing behavior, it appears that the interactions between feed rate and DDGS level were significant. Within the range of the studied parameters of speed and feed, hole entry and exit conditions were satisfactory with relatively sharp edges and minimal chipping.

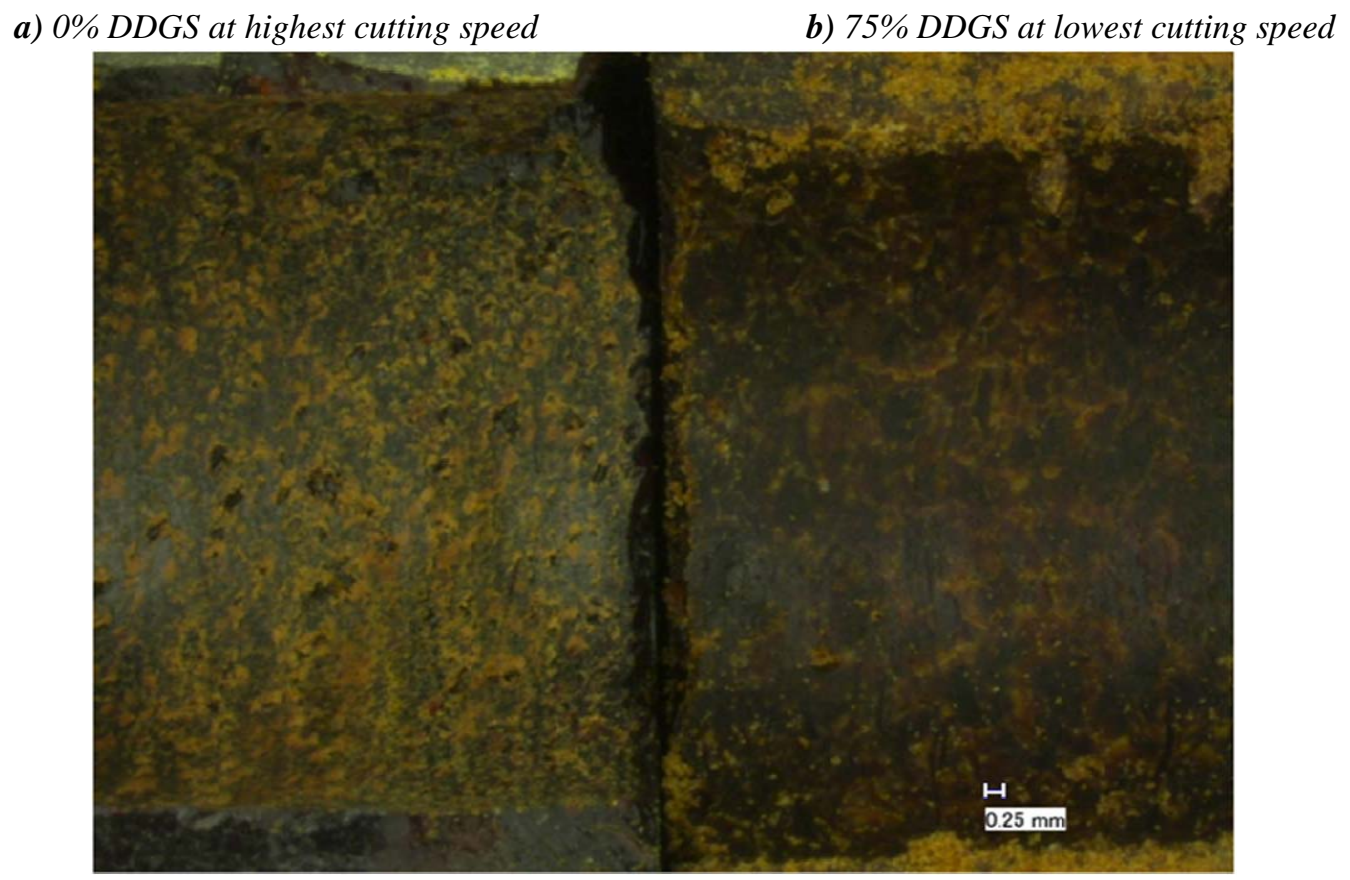

Fig. 6. Microscopic view and side-by-side comparison of drilled slot's wall at the middle feed rate 
Fig. 8 displays the effects of DDGS and cutting speed on the resulting hole diameter. The points represent averages of the experimental data points at the given condition while error bars represent the deviation between the best-fit function and individual data points. From Fig. 8(a), for $100 \%$ phenolic, the resulting average hole diameter was oversized by less than $0.5 \%$, but at $75 \%$ DDGS the resulting hole was undersized by less than $0.5 \%$. As cutting speed increased, hole diameter became larger than nominal. At $17 \mathrm{~m} / \mathrm{min}(55 \mathrm{ft} / \mathrm{min})$ the hole was less than $0.2 \%$ undersized, while at $46 \mathrm{~m} / \mathrm{min}(150 \mathrm{ft} / \mathrm{min})$ it was about $0.25 \%$ oversized. While both of these effects are statistically significant, at $90 \%$ certainty, practically speaking, neither is very large. Fig. 8(c) shows the interaction effects between feed rate and different levels of DDGS. At higher feed rates, the effect of DDGS concentration on hole diameter was minimized, though again this effect was not large. In general, the deviation from nominal hole size was under $0.5 \%$. Again, within Figs. 8(a) and 8(b), through multiple linear regression, a best-fit representation was found to be:

diameter $=\mathrm{A}+\mathrm{B}(\mathrm{DDGS})+\mathrm{C}($ speed $)+\mathrm{D}($ DDGS $\cdot$ feed $)+\mathrm{E}(\mathrm{DDGS} \cdot$ speed $\cdot$ feed $)$

where $\mathrm{A}=9.520 ; \mathrm{B}=-9.07 \times 10^{-4} ; \mathrm{C}=0.00120 ; \mathrm{D}=0.00119$; and $\mathrm{E}=-5.39 \times 10^{-7}$, while diameter is in units of mm, DDGS in \% (by weight), speed in $\mathrm{m} / \mathrm{min}$, and feed in $\mathrm{mm} / \mathrm{rev}$. The coefficient of determination for this fit was 0.42 .

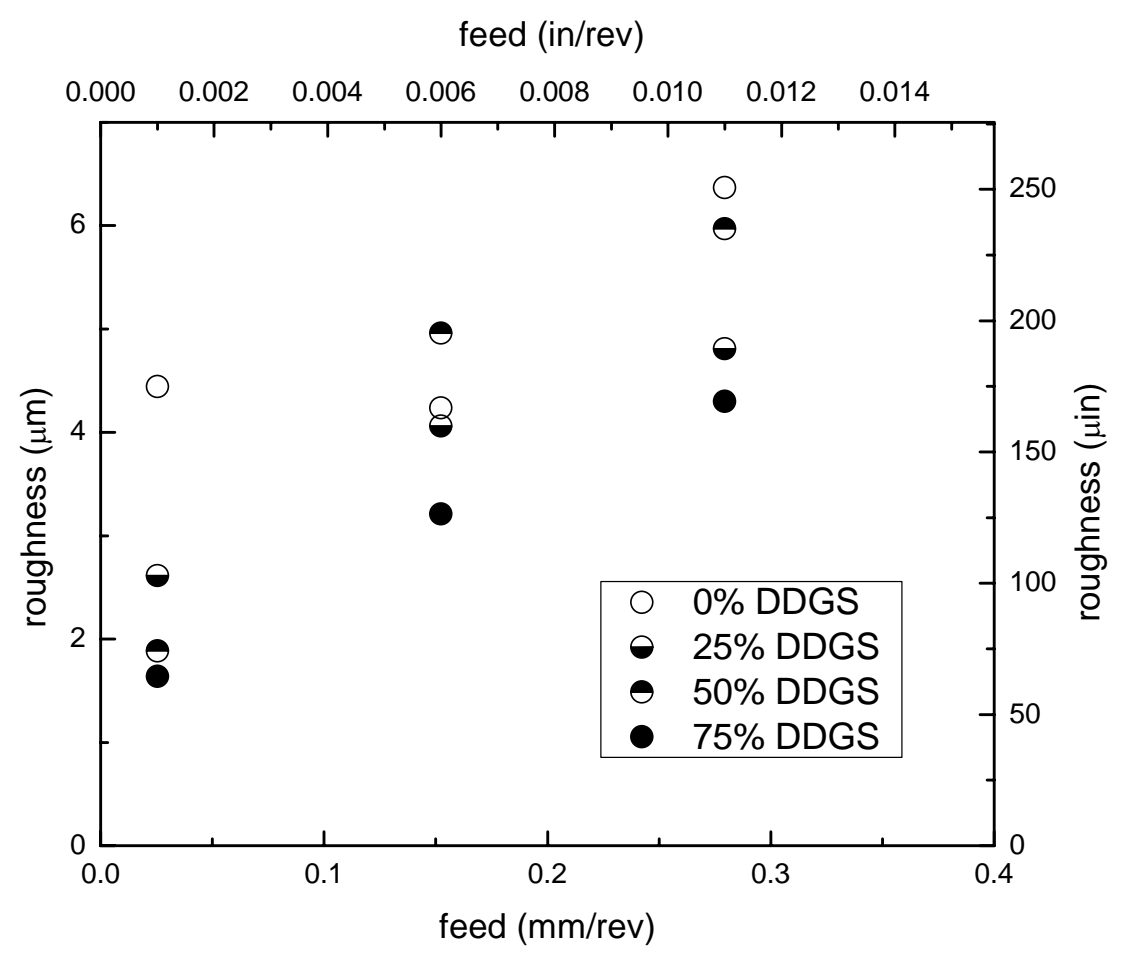

Fig. 7. Interaction plot for feed rate and DDGS 
a) DDGS concentration

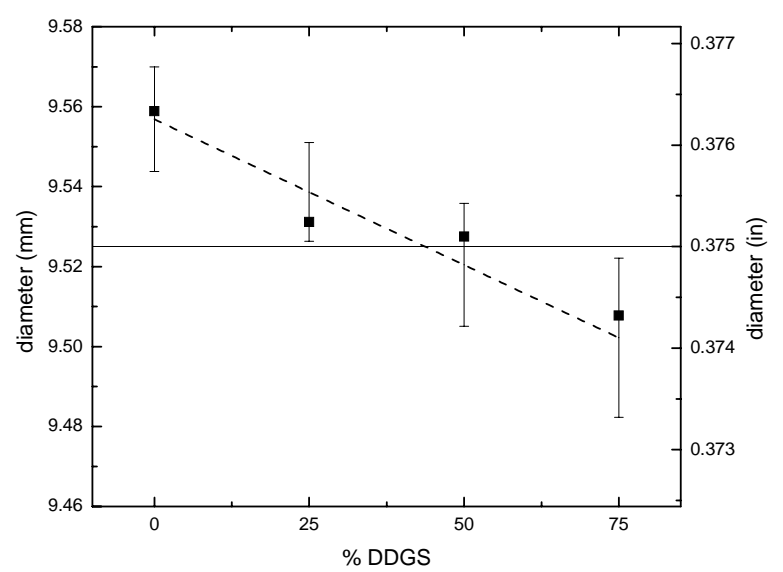

b) Cutting speed

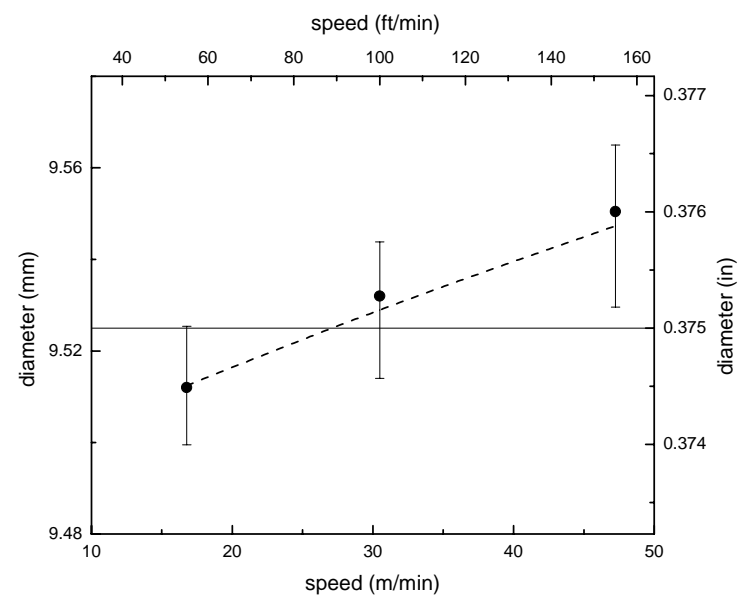

c) Interaction plot of feed rate and DDGS concentration

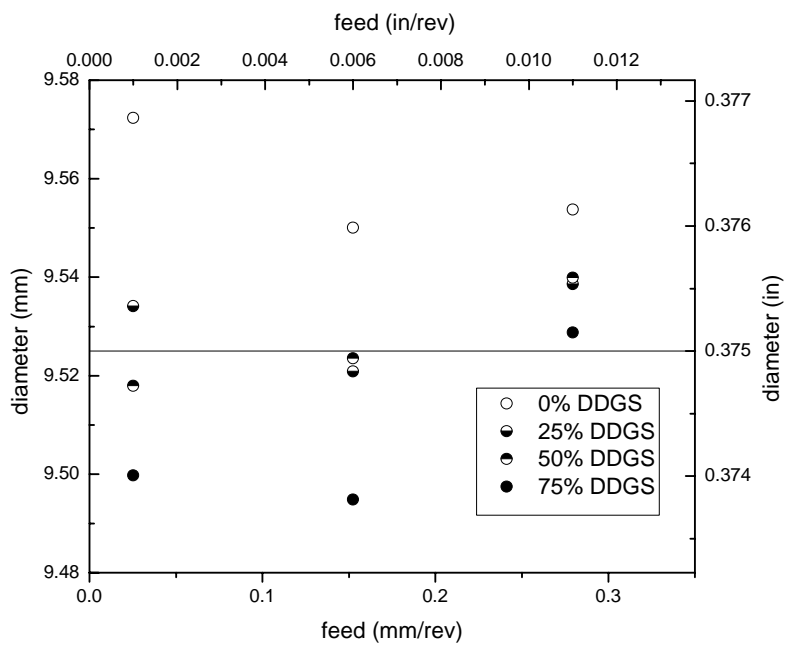

Fig. 8. Effects of drilling parameters upon hole diameter: solid horizontal line is nominal hole size; dashed line represents best-fit function - Eq. (2) 


\section{CONCLUSIONS}

Testing has demonstrated that phenolic resin filled with DDGS may be successfully machined by drilling. Results indicate that as the DDGS content increases, roughness has a weak but statistically significant reduction from $4.3 \mu \mathrm{m}$ (170 $\mu \mathrm{in})$ to $2.7 \mu \mathrm{m}$ (105 $\mu \mathrm{in})$. This can be explained by the release of oils from the DDGS particles as they are deformed and sheared during cutting. Thus, addition of DDGS provides a self-lubrication feature to blends in addition to its use as filler. When cutting speed increases, roughness also slightly increases, from $3 \mu \mathrm{m}$ (125 $\mu \mathrm{in})$ to $3.8 \mu \mathrm{m}(150 \mu \mathrm{in})$. However, roughness increases more with the feed rate - $2.2 \mu \mathrm{m}$ (85 $\mu \mathrm{in})$ to 5.1 $\mu \mathrm{m}(200 \mu \mathrm{in})$ - than with cutting speed. When analyzing for consistency of drilled hole diameter, the effect of greater DDGS content tended to undersize the hole - $9.56 \mathrm{~mm}$ to $9.50 \mathrm{~mm}(0.3764$ in to $0.3740 \mathrm{in}$ ). This may occur from localized thermal expansion in the immediate vicinity of the cutting. However, increasing drilling speed tended to oversize the hole $-9.51 \mathrm{~mm}$ to $9.55 \mathrm{~mm}$ ( 0.3744 in to $0.3760 \mathrm{in}$ ). This is not due to thermal expansion especially since as speed increases holes become more oversized. Instead, the oversizing may stem from deformation transmitted deeper into the material, away from the tool. With increasing speed, this phenomenon becomes more pronounced.

To minimize hole roughness, optimal conditions are 75\% DDGS content, a slower speed of $17 \mathrm{~m} / \mathrm{min}(55 \mathrm{ft} / \mathrm{min})$, and a low feed rate of $0.025 \mathrm{~mm} / \mathrm{rev}(0.001 \mathrm{in} / \mathrm{rev})$. On the other hand, considering diametral consistency, optimal conditions are predicted for $40 \%$ DDGS, $30 \mathrm{~m} / \mathrm{min}$ (100 ft/min), and $0.152 \mathrm{~mm} / \mathrm{rev}$ (0.006 in/rev) in order to maintain the $9.52 \mathrm{~mm}(0.375 \mathrm{in})$ slot.

\section{ACKNOWLEDGEMENT}

This material is based upon work supported by the U.S. Department of Agriculture, Agricultural Research Service, under agreement No. 58-5447-5-319. Any opinions, findings, conclusion, or recommendations expressed in this publication are those of the author(s) and do not necessarily reflect the view of the U.S. Department of Agriculture.

\section{REFERENCES}

1. Mohanty A.K., Seydibeyoglu M.O., Misra M.: Wastes and undervalued coproducts from biofuel industries as raw materials for new industrial products: Greener pathway for a sustainable bioeconomy. SAMPE ’09 Spring Symposium Conference Proceedings, Baltimore, Maryland, 2009.

2. Rosentrater K.A., Otieno A.W.: Considerations for manufacturing bio-based plastic products. J. Polym. Environ. 14 (2006), 335-346.

3. Tatara R.A., Rosentrater K.A., Suraparaju S.: Design properties for molded, corn-based DDGS-filled phenolic resin. Ind. Crop. Prod. 29 (2009), 9-15. 
4. Rosentrater K.A., Otieno A.W., Melampati P.: Determining machining parameters of corn byproduct filled plastics. Intl. J. Mod. Engr. 9(1) (2008), 13-18.

5. Bhadra R., Muthukumarappan K., Rosentrater K.A.: Characterization of chemical and physical properties of distillers dried grain with solubles (DDGS) for value added uses. ASABE Annual International Meeting, Minneapolis, Minnesota, 2007.

6. Shanafield J.W.: Drilling Studies on Compression-molded, DDGS-filled Phenolic Tiles, Master's Thesis, Northern Illinois University, DeKalb, 2011.

7. Lokensgard E.: Industrial Plastics: Theory and Applications. Delmar, New York, 2010, 138-141. 